University of Nebraska - Lincoln

DigitalCommons@University of Nebraska - Lincoln

Educational Psychology Papers and

Publications

Educational Psychology, Department of

January 2007

\title{
Risk and Protective Factors for Children of Adolescents: Maternal Depression and Parental Sense of Competence
}

\author{
Lisa Knoche \\ University of Nebraska-Lincoln, lknoche2@unl.edu \\ Jami E. Givens \\ University of Nebraska-Lincoln \\ Susan M. Sheridan \\ University of Nebraska-Lincoln, ssheridan2@unl.edu
}

Follow this and additional works at: https://digitalcommons.unl.edu/edpsychpapers

Part of the Educational Psychology Commons

Knoche, Lisa; Givens, Jami E.; and Sheridan, Susan M., "Risk and Protective Factors for Children of Adolescents: Maternal Depression and Parental Sense of Competence" (2007). Educational Psychology Papers and Publications. 29.

https://digitalcommons.unl.edu/edpsychpapers/29

This Article is brought to you for free and open access by the Educational Psychology, Department of at DigitalCommons@University of Nebraska - Lincoln. It has been accepted for inclusion in Educational Psychology Papers and Publications by an authorized administrator of DigitalCommons@University of Nebraska - Lincoln. 


\title{
Risk and Protective Factors for Children of Adolescents: Maternal Depression and Parental Sense of Competence
}

\author{
Lisa L. Knoche ${ }^{1, *}$, Jami E. Givens ${ }^{2}$, and Susan M. Sheridan ${ }^{1}$ \\ ${ }^{1}$ Nebraska Center for Research on Children, Youth, Families and Schools (CYFS), Uni- \\ versity of Nebraska, Lincoln, 238 Teachers College Hall, Lincoln, NE 68588-0345 \\ ${ }^{2}$ Department of Educational Psychology, University of Nebraska, Lincoln, Lincoln, NE \\ *Corresponding author.Email: 1knoche2@unl.edu
}

\begin{abstract}
We investigated the relationship between depression and parental sense of competence to child cognitive outcomes for a sample of 49 adolescent mothers and their young children (Mean age $=91 / 2$ months) enrolled in a student parenting program. Cognitive development of the infants and toddlers was assessed using the Bayley Scales of Infant Development. Maternal depression was assessed with the CES-D and parental competence measured with the Parental Sense of Competence Scale. Results indicated that maternal depression and parental sense of competence alone did not predict children's cognitive scores; the interaction of the variables significantly predicted children's outcomes. Mothers reporting high levels of depression, who self-reported high levels of parental competence, had children who scored higher on the Bayley. Children of mothers with high levels of depression, and low reported levels of competence scored lower on the Bayley. The relationship was not significant for mothers reporting low levels of depression. Our findings suggest additional research needs to focus on the buffering effect of parental sense of competence for adolescent mothers experiencing depression.
\end{abstract}

Keywords: Adolescent mothers, Maternal depression, Parental sense of competence, Infant/toddler development, Adolescent parenting programs

To adequately understand children, we must understand the ecological contexts within which they grow and develop (Bronfenbrenner, 1979). Children do not develop in isolation, but instead participate in multiple interacting systems that affect their growth (Bronfenbrenner, 1977; Rogoff, 1991). A variety of factors influence children's development, including innate child characteristics (e.g., temperament, ability, interest), environmental features (e.g., parental characteristics, family circumstances, neighborhood characteristics), and their interaction. These ecological contexts create conditions for optimal or 
compromised developmental trajectories. Young children's experiences prior to school entry also play a crucial role in shaping their early literacy and language skills (Morrison \& Cooney, 2002). Indeed, because a child's early environment influences later cognitive outcomes (including those related to school readiness and academic success), understanding the impact of specific environmental and parental characteristics is important.

In light of the relevance of context, young children of adolescent parents experience a particularly unique developmental milieu that likely contributes to cognitive outcomes, including language and literacy skills. The adolescent birth rate in the United States continues to be higher than that of any other industrialized country (Singh \& Darroch, 2000). Approximately 750,000 adolescent girls become pregnant each year, with half of these pregnancies resulting in live births. Of the adolescents whose pregnancies result in a live birth, approximately $90 \%$ choose to keep the child rather than to put the child up for adoption (Borkowski, Bisconti, Willard, Keogh, \& Whitman, 2002, 10\% of all births were to mothers under age 20 (Child Trends, 2006). Though the adolescent birth rate has declined since 1990, the rate of decline has diminished; between 2003 and 2004, the number of births to girls under age 15 increased, as did the number of births to Hispanic teens. There was also a slight increase in the percentage of repeat births over the same time period (Child Trends, 2006). Given these statistical trends, investigating factors contributing to development in children of adolescent parents continues to be relevant.

Adolescent parents, along with their children, face unique challenges. At least 40,000 adolescents who become pregnant drop out of school each year and less than $60 \%$ of adolescent mothers graduate from high school by age 29 (Pianta \& Walsh, 1996). Lack of education presents significant obstacles for adolescents and their children. In addition, adolescent parents have emotional risk factors (e.g., complete less than twelve years of education, single mother) that have been found to be associated with dire child outcomes, including lower levels of language skills and delayed cognitive development (Griffin \& Morrison, 1997; Sameroff \& Fiese, 2000; Stanton-Chapman, Chapman, Kaiser, \& Hancock, 2004).

Adolescent mothers face challenges related to providing rich language and home literacy experiences for their children. These characteristics are important to consider when investigating young children's development, as they have been linked positively to cognitive development in children (Bradley et al., 1989; Griffin \& Morrison, 1997). Adolescent mothers have been found to initiate fewer verbal interactions and are not as physically responsive to their children as older mothers (Culp, Appelbaum, \& Osofsky, 1988; Porter, 1990), factors that affect the developmental progress of their young children. In particular, children of adolescent mothers typically show lower levels of cognitive development and performance in school than children of adult mothers (Brooks-Gunn \& Furstenberg, 1986; Hayes, 1987; Moore, Morrison, \& Greene, 1997). One study reported that almost $3 / 4$ of children born to adolescent mothers had one developmental problem by age 3 , and that language development, a particular component of cognition, was often delayed (Borkowski et al., 2002).

When adolescents become parents, their new role often brings a great deal of stress and social-emotional maladjustment (Borkowski et al., 2002; East \& Felice, 1996). Adolescents may lack the preparation to meet not only the financial, but also the interpersonal challenges of parenting, including physical exhaustion, isolation, and lack of support (Birkeland, Thompson, \& Phares, 2005). Adolescent mothers are likely to raise their child without the presence of the child's biological father or a stable male role model (Borkowski et al., 2002). Furthermore, adolescent mothers often have insufficient income, resulting in poverty. 
Children experiencing poverty have significant challenges related to early learning (Baydar, Brooks-Gunn, \& Furstenberg, 1993; Smith, Brooks-Gunn, \& Klebanov, 1997).

Given these adverse characteristics, adolescent parents, specifically adolescent mothers, face an increased risk for psychological problems. In fact, young mothers are twice as likely to experience depression as adult mothers (Deal \& Holt, 1998). On average 1 in 10 mothers report depressive symptoms (Gelfand, Teti, Seiner, \& Jameson, 1996), with higher prevalence rates for mothers in poverty. A study of adolescent mothers found that $29 \%$ met criteria for clinical depression (Birkeland et al., 2005). This finding suggests that adolescent mothers experience higher levels of depression than adult mothers.

As a result, depressed adolescent mothers have been found to experience more psychosocial stressors than non-depressed mothers (e.g., physical health, mental health, peer relations, family relations, vocational status, and social skills) (Prodromidis, Abrams, Field, Scafidi, \& Rahdert, 1994). Mothers with these additional psychosocial stressors, including depression, are not always able to effectively manage the tasks of motherhood (Gelfand \& Teti, 1990). Maternal depression has been found to be related to a host of adverse infant and child outcomes including insecure attachment and behavioral problems (Murray, 1992). Infants of depressed mothers are reported to be more irritable, less active, less responsive, and less physically developed than infants of mothers who are not depressed (Field, 1998). Maternal depression has been associated with insensitive and negative mother-child interactions (Murray, Fiori-Cowley, Hooper, \& Cooper, 1996), undesirable parenting practices, and an inability to meet the needs of young children (Gelfand \& Teti, 1990). Infants of depressed mothers exhibit non-optimal behaviors at birth (e.g., unavailability, lethargy, and stress behaviors), which may contribute to the difficult motherchild interactions experienced by depressed mothers (Abrams, Field, Scafidi, \& Prodromidis, 1995). Difficult mother-child interactions often contribute to non-optimal child outcomes later in life (e.g., social and emotional development).

As a result, maternal depression has been considered a risk factor for children's development (Abrams et al., 1995; Rutter, 1990) and cognitive outcomes (Field et al., 1995; Petterson \& Albers, 2001). For example, Petterson and Albers (2001) found that maternal depression had an adverse impact on the cognitive and motor development of children, ages 28 to 50 months. Similarly, infants of depressed mothers have been found to engage in less exploratory play at 12 months, with maternal depression proving the strongest contributor to low cognitive outcomes (Field et al., 1995).

Though many studies have investigated effects for children of depressed mothers, few studies to date have investigated the effects of maternal depression in adolescent mothers and its effects on children's cognitive outcomes. Thus, additional research is needed to fully understand the impact of adolescent maternal depression on child outcomes.

Although maternal mental health factors such as depression may be related to negative developmental trajectories for children, certain variables have been found to promote positive child outcomes. Maternal self-efficacy beliefs have been found to be related to effective parenting behaviors (Bondy \& Mash, 1999; Coleman \& Karraker, 2000; Coleman, Trent, Bryan, King, Rogers, \& Nazir, 2002) and children's developmental status (Coleman \& Karraker, 2003; Coleman et al., 2002). Self-efficacy, as a general cognitive construct, is a set of beliefs concerning one's ability to carry out and perform effectively in a particular setting or task (Raikes \& Thompson, 2005). Maternal self-efficacy is defined as a mother's sense of competence in the maternal role and the perception of her ability to positively influence the behavior and development of her children (Coleman \& Karraker, 2000). Par- 
ents with high levels of self-efficacy have been found to engage in more positive parenting behaviors (Coleman \& Karraker, 2000; Raikes \& Thompson, 2005; Teti \& Gelfand, 1991). In particular, Coleman and Karraker (2000) state that "high parenting self-efficacy seems to be associated with the parental capacity to provide an adaptive, stimulating, and nurturing child-rearing environment" (p. 13). High maternal self-efficacy can directly affect children by leading to more positive maternal behaviors, including more responsive and less-punitive caretaking, attention to infant signals, and more active and directive parenting interactions (Coleman \& Karraker, 2000).

Conversely, low levels of self-efficacy have been associated with parental depression, high levels of stress, maternal learned helplessness, child behavior problems, parental defensive and controlling behaviors, and parental perceptions of child difficulty (Coleman \& Karraker, 2000). Parenting confidence has been predictive of children's socioemotional well-being; when adolescent mothers experience low levels of maternal selfefficacy, children are more likely to be socially-withdrawn (East \& Felice, 1996).

In regard to children's cognitive outcomes, Coleman and Karraker (2003) found that domain-specific parental reports of self-efficacy (i.e., perceptions of parental emotional availability, nurturance, ability to play with child, discipline, teaching, instrumental care, and ability to protect child) was significantly related to children's Mental Development Index (MDI) scores on the Bayley Scales of Infant Development-II (BSID-II; Bayley, 1993). Additionally, parental competence was significantly positively related to children's MDI scores (Coleman \& Karraker, 2003). Despite the information known for parents in general, minimal research exists on the specific parenting efficacy/competence of adolescent parents and the corresponding outcomes for their children (Chase-Lansdale, Brooks-Gunn, \& Paikoff, 1991; Fulton, Murphy, \& Anderson, 1991; Secco, Ateah, Woodgate, \& Moffatt, 2002).

The lack of research on this topic demonstrates a need for more studies addressing the relation of parental competence and self-efficacy to outcomes for children of adolescent parents. Although research on self-efficacy and parenting have been the focus for many researchers (e.g., Coleman \& Karraker, 2000, 2003; Johnston \& Mash, 1989; Raikes \& Thompson, 2005), maternal self-efficacy, as it relates to the needs and demands of teen parenting, remains relatively unexplored.

Little is known about the role of depression and parental sense of competence for adolescent parents in relation to their children's development; even less is known about how parental competence, as a construct of maternal efficacy, interacts with maternal depression to predict child outcomes, particularly for adolescent mothers. Because depression and parental sense of competence are both known to affect parenting behaviors and contribute to child outcomes in the parenting population at-large, it is reasonable to examine the interaction of these predictors and their combined influence on young children's cognitive development.

We examined the predictive effects of depression and parental sense of competence, including their interaction on child developmental outcomes for adolescent mothers in a high school student parenting program. Specifically, we sought to answer two primary research questions: (1) what is the bivariate relation between depression, parental sense of competence and child cognitive development for a group of adolescent mothers, and (2) does maternal depression and parental sense of competence predict child cognitive development?

\section{Method}

Our study is part of a larger longitudinal investigation examining the effects of an intervention to promote school readiness and parental engagement among children and fami- 
lies living in low socioeconomic conditions at risk for academic, socioemotional, and behavioral difficulties. It involves a subset of data concerning adolescent parents, whereas the larger investigation examines effects for a sample of Head Start and Early Head Start families with children from ages birth to 5 (Sheridan \& Edwards, 2006).

\section{Participants}

The participants in our study were 49 adolescent mothers in grades nine through twelve (mean age $=17.3$ years; range 14 to 21 years) recruited from local high schools in a Midwestern community. The self-reported ethnic classifications of adolescent mothers who participated in the study were 44\% Caucasian, 22\% African American, 16\% Hispanic/Latino, $6 \%$ American Indian/Alaskan Native. Another $10 \%$ of mothers reported an ethnic classification as "other." In addition, their children (20 males and 29 females) also served as participants (mean age $=9.6$ months; range 1 to 35 months).

\section{Setting}

Our study took place in public secondary schools in a mid-sized Midwestern community. Mothers and children were enrolled in one of four high school student parenting programs based in their high schools. Mothers and children who had plans to remain in the program for one year or more were eligible for participation. The adolescent mothers attended high school classes while their children were cared for in a child development center based in the high school. The mothers participated in a parenting class each academic quarter their children were enrolled in the child development center. The mission of the student parent program is to assist adolescent parents by providing educational and community supports. The goals of program include (a) increasing the number of adolescent parents who graduate from high school, (b) providing preventive interventions, and (c) increasing parenting quality.

\section{Measures}

Several empirically supported self-report measures were used to assess parent variables hypothesized to predict child outcomes. Standardized measures were used to collect information on child functioning and cognitive outcomes.

Depression and parental efficacy were the independent variables used in this investigation. The Center for Epidemiologic Studies Depression Scale (CES-D; Radloff, 1977) is a 12-item, 4-point Likert scale used to measure levels of depressive symptomology among the adolescent mothers. Higher scores on the item set were characteristic of higher levels of depressive symptomology. Scores range from 0 to 60 , with clinical levels of depression indicated by scores of 16 or more. Radloff (1977) reported high levels of internal consistency among all 20-items, ranging from 0.84 to 0.90 . Mothers also completed the Parental Sense of Competence Scale (PSOC; Johnston \& Mash, 1989) as a measure of their perceived self-efficacy and satisfaction in their maternal role. The total scale score, including efficacy and satisfaction, was used for this investigation; average PSOC ranges from 1 to 6 , with higher scores indicating a greater sense of parental competence. The total scale, consisting of 16 items, has been found to have an internal consistency of 0.79 .

Child cognitive development is the dependent variable of interest. The Bayley Scales of Infant Development-Second Edition (BSID-II; Bayley, 1993) were used to assess cognitive, language, and personal-social functioning of the infant and toddler participants. For the focus of our study the mental development index (MDI) of the BSID-II was utilized. The BSID-II is a standardized instrument, and has been used widely to assess infant and 
toddler development; the average score is 100, standard deviation is 15. Bayley (1993) reported acceptable split-half reliability coefficients of 0.88 using a standardization sample of over 1200 children ages 2-30 months.

\section{Procedure}

Following receipt of informed consent, mothers participated in individual guided interviews with graduate student research assistants at each respective high school. Child data were collected in the child development centers located within the high schools in individual assessment sessions. Baseline data were used from all of the participating adolescent mothers and children, prior to their involvement in the larger intervention project. As a result of their participation in the study, mothers received a $\$ 35$ gift card to a local store.

\section{Analytic techniques}

To address the first research question, correlation analyses were conducted to investigate the bivariate relationship between depression, parental sense of competence, and child cognitive development. For the second research question, multiple regression analyses were conducted to predict the cognitive outcomes of young children born to adolescent parents. The analysis included depression, parental sense of competence, and their interaction as predictors of children's cognitive outcomes.

\section{Results}

Initial descriptive statistics were analyzed for independent and dependent variables (see Table 1). Correlation coefficients were computed among the CESD, PSOC, Bayley, maternal age, and child age (see Table 2). Three of the bivariate correlations were statistically significant. The bivariate results indicate that as adolescent mothers' depression increases, their children score lower on the Bayley. Additionally, higher levels of parental sense of competence in the adolescent mothers related to higher child scores on the Bayley. Depression and sense of competence were negatively related; that is, as depression increased, parental sense of competence diminished. The significant bivariate correlation between depression and parental sense of competence yields further evidence that the two predictors might interact to predict child outcomes. Maternal age and child age were not statistically related to any of the variables, and were therefore not included in the subsequent analyses.

Table 1 Summary descriptive statistics of key study variables

\begin{tabular}{lrrl}
\hline Variable & Mean & SD & Cronbach's Alpha \\
\hline Cognitive Outcomes (Bayley MDI) $^{a}$ & 91.70 & 10.77 & n/a \\
Depression (CESD) $^{b}$ & 11.69 & 8.89 & 0.85 \\
Parental sense of competence (PSOC) $^{c}$ & 4.60 & 0.63 & 0.77 \\
\hline
\end{tabular}

${ }^{a}$ MDI- Mental Development Index; $M=100 ; S D=15$.

${ }^{b}$ Scores range from 1 to 60 , with clinical levels of depression suggested by scores $\geq 16$.

${ }^{c}$ Item mean scores range from 1 to 6 with higher levels indicated greater levels of reported competence. 
Table 2 Summary of bivariate correlations between child cognitive outcomes, maternal depression, parental sense of competence, maternal and child ages

\begin{tabular}{lrrrrr}
\hline Variables & 1 & 2 & 3 & 4 & 5 \\
\hline 1. Cognitive outcomes & & & & & \\
2. Depression & $-0.37^{*}$ & & & & \\
3. Parental competence & $0.39^{* *}$ & $-0.58^{* *}$ & & & \\
4. Maternal age & -0.13 & 0.28 & -0.28 & & \\
5. Child age & 0.02 & 0.05 & -0.09 & 0.22 \\
\hline
\end{tabular}

${ }^{*} p \leq .05 ;{ }^{* *} p \leq .01 ;{ }^{* * *} p \leq .001$

Because we were interested in the unique effects of depression, parental sense of competence and the interaction of these variables on children's cognitive scores, multiple regression analysis was utilized. Per recommended practice, the independent variables were mean centered to yield a more logical interpretation of the intercept and reduce collinearity between the predictors and the interaction (Holmbeck, 1997).

The regression model produced a significant effect, $R^{2}=.38$, adjusted $R^{2}=.34$, $\mathrm{F}(3,42)=8.72, p<.01$ (see Table 3 ). The model predicts $38 \%$ of the variance in child cognitive outcomes. Depression, when controlling for the effects of parental sense of competence and the interaction term, was not significantly predictive of child scores on the Bayley. Similarly, parental sense of competence, when controlling for the effects of depression and the interaction term, was not statistically significant. However, there was a significant interaction between maternal depression and parental sense of competence. The interaction plot is depicted in Fig. 1.

Further analysis of the interaction determined that the relationship between parental sense of competence and children's scores on the Bayley differed by level of maternal depression. Post-hoc tests of the slope of the regression lines indicated that the slope of the line for mothers experiencing high levels of depression was significantly different from zero (mothers with mean levels of depression) $(t=2.84, p<.01)$. For children of parents with high levels of depression (one standard deviation above the mean; CESD $=20.37$ ), high levels of parental sense of competence (one standard deviation above the mean; PSOC $=5.21$ ) related to higher scores the Bayley. The significant interaction indicates that when parents have high levels of depression, and have high levels of parental competence, their children have higher scores on the Bayley than adolescent parents with low levels of parental sense of competence (one standard deviation below mean; PSOC = 3.98). Furthermore, children of depressed parents who have low parental competence have children with lower Bayley scores.

Table 3 Summary of multiple regression analysis for variables predicting child cognitive outcomes as measured by the bayley scales of infant development $(N=49)$

\begin{tabular}{lrcc}
\hline Variable & \multicolumn{1}{c}{$B$} & SE B & \multicolumn{1}{c}{$\beta$} \\
\hline (Constant) & 93.68 & 1.41 & \\
Depression (CESD) & -0.04 & 0.19 & -0.03 \\
Parental Sense of Competence (PSOC) & 2.21 & 2.63 & 0.13 \\
Interaction PSOC $\times$ CESD & 0.61 & 0.17 & $0.53^{* *}$ \\
\hline
\end{tabular}

Note. $R^{2}=0.38^{* *}$.

${ }^{*} p \leq .05 ;{ }^{* *} p \leq .01 ;{ }^{* *} p \leq .001$. 


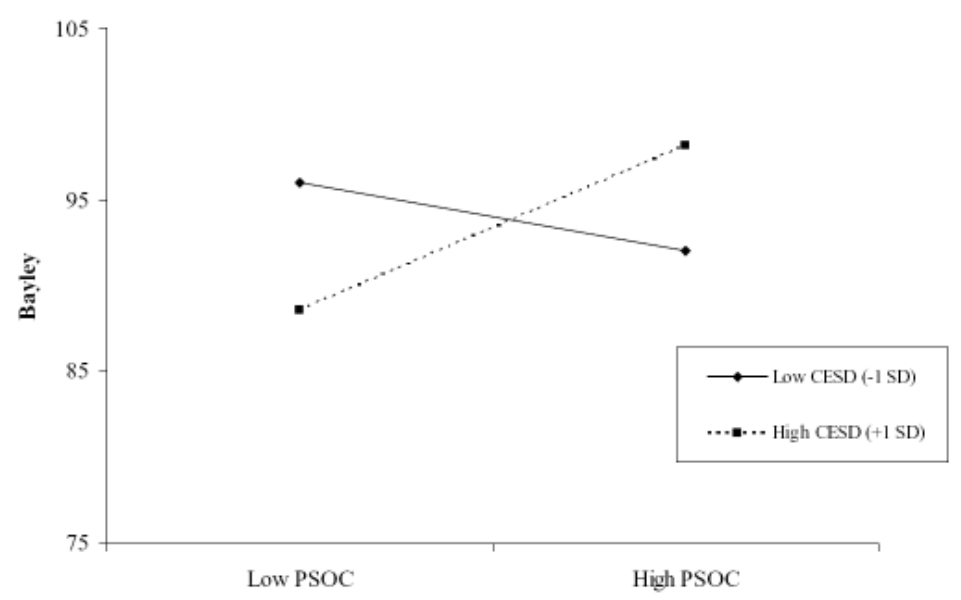

Figure 1 Relation between parental sense of competence and child cognitive outcomes as moderated by maternal depression

Post-hoc tests of the slope of the regression line for mothers with low levels of depression (one standard deviation below mean; CESD $=2.73$ ) revealed that this group was not significantly different from zero $(t=-.99, p>.05)$. For parents with low levels of depression in this sample, parental sense of competence is not related to children's Bayley scores.

\section{Discussion}

We investigated the relationship between maternal depression and parental sense of competence, as well as their interaction, to child cognitive development. Children of adolescents experience a unique developmental landscape. Knowing that the contexts of children and families greatly contribute to developmental trajectories, it is important to consider the developmental outcomes of children of adolescent parents, and understand the correlates of development. This group is at unique risk for developmental challenges (Griffin \& Morrison, 1997; Pianta \& Walsh, 1996; Sameroff \& Fiese, 2000; StantonChapman et al., 2004). In an effort to facilitate the most effective method of intervention, it is important to determine the specific factors which place these children at-risk for cognitive deficits.

Previous literature has shown that depression and parental sense of competence are related to child outcomes. The relationship of these variables for adolescent parents in particular is less understood. In our study, bivariate analyses revealed that both parental sense of competence and depression relate to the child outcome measure. However, upon using a multivariate analysis, the significance is lost. Results indicate that depression and parental sense of competence alone do not predict child cognitive outcomes for this sample. To understand the predictive power of these variables, we must consider how they work together. It is the interaction of depression and parental sense of competence that statistically significantly predicts children's scores on the Bayley.

When adolescent parents report high levels of depression, parental sense of competence is important in predicting child outcome scores as measured by the Bayley. These findings are consistent with previous studies on parental efficacy; efficacy and satisfac- 
tion in parenting are related to child well-being (Coleman \& Karraker, 2003; Raikes \& Thompson, 2005; Teti \& Gelfand, 1991), but run counter to studies that have shown maternal depression to negatively relate to child outcomes (Abrams et al., 1995; Petterson \& Albers, 2001; Rutter, 1990). Parental sense of competence, in some ways, is acting as a "buffer" for children. Despite experiencing depression, adolescent parents who can develop an enhanced sense of parental competence-perhaps a feeling of proficiency in a single domain of their often chaotic lives-will support positive cognitive outcomes in their children. This is an important area for intervention work with adolescent parents. In addition, further research is needed to investigate the possible buffering effect of parental competence on adolescent parents experiencing depression.

When parents are experiencing low levels of depression, children's Bayley scores are not related to levels of parental sense of competence. Parental sense of competence does not have the same "buffer" characteristic when adolescent parents are not experiencing depression; perhaps there are other characteristics and influences that contribute significantly to child outcomes for this group. This is an area of research that warrants further investigation. Taking into account paternal, as well as maternal depression is also worthy of investigation.

The role of depression and parental sense of competence in relation to parenting behaviors and family literacy activities for adolescent parents should also be the focus of further investigation. Perhaps depression and parental sense of competence are independently related to parenting behaviors and activities and not child outcomes. That is, these variables could be affecting the behaviors parents display in their interactions with their children and affects what is happening to support the children's development in home and community contexts. The parental behaviors, in turn, contribute to child outcomes. Additional characteristics of adolescent parents should also be considered, including parenting knowledge, parenting stress, and general knowledge of child development. Pas studies have indicated these as worthy correlates of child outcomes (East \& Felice, 1996).

Findings from our study must be interpreted with caution, given some limitations to the research. First, depression and parental sense of competence are self-report measures. Though the CES-D has been used widely as a proxy for depression, respondents could respond based on social desirability. Likewise, the parental competence ratings provided by mothers represent beliefs and self-perceptions, and are not reflective of actual parenting practices.

Second, the findings are generalizable only to adolescent parents in similar parenting programs who are enrolled in high schools. Mothers and children who had plans to remain in the program for one year or more were eligible for participation; this qualification excluded some adolescent mothers and children from the study. Participation in the student parenting program could facilitate enhanced parental sense of competence, as well as moderate parental levels of depression. Though this issue limits the generalizability of the findings from our study, investigating the interaction effects of program characteristics and parental ratings of competence and depression is an area fruitful for future research.

\section{Implications for practice}

Research indicates that exposure to risk factors influences child development, including the development of pre-academic school readiness skills (Evans \& English, 2002; Halpern, 2000; Stanton-Chapman et al., 2004). By understanding factors related to the cognitive development of the young children of adolescent mothers, professionals can develop 
and implement preventative and intervention techniques to effectively serve young children and their adolescent mothers.

Interventions focused on adolescent parents who are experiencing depression are critically important. Adolescent parents might be screened for mental health concerns, including depression; once identified, specific programs can be implemented to address concerns. As the findings from our study suggest, for parents who are experiencing depression, high levels of parental sense of competence serve as a protective factor for their children's development. Efforts made by professionals to improve parental sense of competence in a parent who is experiencing above average levels of maternal depression can result in positive gains for her child.

Ecological contexts are a critical component in influencing young children's development (Bronfenbrenner, 1979). This is particularly true for children born to adolescents. Maternal depression is a risk factor for children, and may have an additive negative influence for young children of adolescents. Past literature has indicated that parental sense of competence may serve as a protective factor. In the current study, these variables interact, whereby parental sense of competence buffers the effect of maternal depression on child cognitive outcomes. Establishing the relation between these variables, and their association to child cognitive outcomes further helps explain the developmental and ecological context for children of adolescents.

Acknowledgments This work was supported through funding provided by NIH Grant \# 1R01H00436135, Parent Engagement and Child Learning, Birth to Five: The Getting Ready Project, awarded to Drs. Susan Sheridan and Carolyn Pope Edwards at the University of Nebraska-Lincoln. The authors would like to thank the families and staff involved in the student parent programs for their participation in the project.

\section{References}

Abrams, S. M., Field, T., Scafidi, F., \& Prodromidis, M. (1995). Newborns of depressed mothers. Infant Mental Health Journal, 16, 233-239.

Baydar, N., Brooks-Gunn, J., \& Furstenberg, F. F. (1993). Early warning signs of functional illiteracy: Predictors in childhood and adolescence. Child Development, 64, 815-829.

Bayley, N. (1993). Bayley scales of infant development: Manual (2nd ed.). New York: Psychological Corporation.

Birkeland, R., Thompson, J. K., \& Phares, V. (2005). Adolescent motherhood and postpartum depression. Journal of Clinical Child and Adolescent Psychology, 34, 292-300.

Bondy, E. M., \& Mash, E. J. (1999). Parenting efficacy, perceived control over caregiving failure, and mothers' reactions to preschool children's misbehavior. Child Study Journal, 29, 157-173.

Borkowski, J. G., Bisconti, T., Willard, C. C., Keogh, D. A., \& Whitman, T. L. (2002). The adolescent as parent: Influences on children's intellectual, academic, and socioemotional development. In J. G. Borkowski, S. L. Ramey, \& M. Bristol-Power (Eds.), Parenting and the child's world (pp. 161-184). Mahwah, NJ: Lawrence Erlbaum Associates.

Bradley, R. H., Caldwell, B. M., Rock, S. L., Ramey, C. T., Barnard, K. E., Gray, C., Hammong, S., et al. (1989). Home environment and cognitive development in the first 3 years of life: a collaborative study involving six sites and three ethnic groups in North America. Developmental Psychology, 25, 217-235.

Bronfenbrenner, U. (1977). Toward an experimental ecology of human development. American Psychologist, 513-531. 
Bronfenbrenner, U. (1979). The ecology of human development. Cambridge, MA: Harvard University Press.

Brooks-Gunn, J., \& Furstenberg, Jr. (1986). Antecedents and consequences of parenting: The case of adolescent motherhood. In A. Fogel \& G. F. Melson (Eds.), Origins of nurturance: Developmental, biological and cultural perspectives on caregiving (pp. 232-258). Hillsdale, NJ: Lawrence Erlbaum Associates.

Chase-Lansdale, L. P., Brooks-Gunn, J., \& Paikoff, R. L. (1991). Research and programs for adolescent mothers: Missing links and future promises. Family Relations, 40, 396-403.

Child Trends. (2006). Facts at a glance 2006: Trends in teen childbearing in the nation, states and large cities. Retrieved May 1, 2006 from http://www.childtrends.org/files/faag2006.pdf

Coleman, P. K., Trent, A., Bryan, S., King, B., Rogers, N., \& Nazir, M. (2002). Parenting behavior, mothers' self-efficacy beliefs, and toddler performance on the Bayley Scales of Infant Development. Early Child Development and Care, 172, 123-140.

Coleman, P. K., \& Karraker, K. H. (2000). Parenting self-efficacy among mothers of school-age children: Conceptualization, measurement, and correlates. Family Relations, 49, 13-24.

Coleman, P. K., \& Karraker, K. H. (2003). Maternal self-efficacy beliefs, competence in parenting, and toddlers' behavior and developmental status. Infant Mental Health Journal, 24, 126-148.

Culp, R., Appelbaum, M. I., Osofsky, J. D., \& Levy, J. (1988). Adolescent and older mothers: Comparison between prenatal maternal variables and newborn interaction measures. Infant Behavior and Development, 11, 353-362.

Deal, L. W., \& Holt, V. L. (1998). Young maternal age and depressive symptoms: Results from the 1988 National Maternal and Infant Health Survey. American Journal of Public Health, 88, 266-270.

East, P. L., \& Felice, M. E. (1996). Adolescent pregnancy and parenting: Findings from a racially diverse sample. Mahwah, NJ: Lawrence Erlbaum.

Evans, G. W., \& English, K. (2002). The environment of poverty: Multiple stressor exposure, psychophysiological stress, and socioemotional adjustment. Child Development, 73, 1238-1248.

Field, T., Estroff, D. B., Yando, R., del Valle, C., Malphurs, J., \& Hart, S. (1995). "Depressed" mothers' perceptions of infant vulnerability are related to later development. Child Psychiatry and Human Development, 27, 43-53.

Fulton, A. M., Murphy, K. R., \& Anderson, S. L. (1991, Spring). Increasing adolescent mothers' knowledge of child development: An intervention program. Adolescence, 26, 73-81.

Gelfand, D. M., \& Teti, D. M. (1990). The effects of maternal depression on children. Clinical Psychology Review, 10, 329-353.

Gelfand, D. M., Teti, D. M., Seinr, S. A., \& Jameson, P. G. (1996). Helping mothers fight depression: Evaluation of a home-based intervention program for depressed mothers and their infants. Journal of Clinical Child Psychology, 25, 406-422.

Griffin, E. A., \& Morrison, F. J. (1997). The unique contribution of home literacy environment to differences in early literacy skills. Early Child Development and Care, 127-128, 233-243.

Halpern, R. (2000). Early intervention for low-income children and families. In J. P. Shonkoff \& S. J. Meisels (Eds.), Handbook of early childhood intervention (2nd ed., pp. 361-386). New York: Cambridge University Press.

Hayes, C. (1987). Risking the future: Adolescent sexuality, pregnancy, and childbearing. Washington, DC: National Academy Press.

Holmbeck, G. (1997). Toward terminological, conceptual and statistical clarify in the study of mediators and moderators: Examples from the child-clinical and pediatric psychology literatures. Journal of Consulting and Clinical Psychology, 65, 599-610.

Johnston, C., \& Mash, E. J. (1989). A measure of parenting satisfaction and efficacy. Journal of Clinical Child Psychology, 18, 167-175.

Moore, K. A., Morrison, D. R., \& Greene, A. D. (1997). Effects on children born to adolescent 
mothers. In R. Maynard (Ed.), Kids having kids (pp. 145-180). Washington, DC: The Urban Institute Press.

Morrison, F. J., \& Cooney, R. R. (2002). Parenting and academic achievement: Multiple paths to early literacy. In J. G. Borkowski, S. L. Ramey, \& M. Bristol-Power (Eds.), Parenting and the child's world: Influences on academic, intellectual, and social-emotional development (pp. 141160). London: Lawrence Erlbaum Associates.

Murray, L. (1992). The impact of postnatal depression on infant development. Journal of Child Psychiatry and Allied Disciplines, 33, 543-561.

Murray, L., Fiori-Cowley, A., Hooper, R., \& Cooper, P. (1996). The impact of postnatal depression and associated adversity on early mother-infant interactions and later infant outcome. Child Development, 67, 2512-2526.

Pianta, R. C., \& Walsh, D. J. (1996). High-Risk children in schools: Constructing sustaining relationships. New York: Routledge.

Petterson, S. M., \& Albers, A. B. (2001). Effects of poverty and maternal depression on early child development. Child Development, 72, 1794-1813

Porter, C. P. (1990). Clinical and research issues related to teen mothers' childrearing practices. Issues in Comprehensive Pediatric Nursing, 13, 41-58.

Prodromidis, M., Abrams, S., Field, T., Scafidi, F., \& Rahdert, E. (1994). Psychosocial stressors among depressed adolescent mothers. Adolescence, 29, 331-343

Radloff, L. S. (1977). The CES-D Scale: A self-report depression scale for research in the general population. Applied Psychological Measurement, 1, 385-401.

Raikes, H. A., \& Thompson, R. A. (2005). Efficacy and social support as predictors of parenting stress among families in poverty. Infant Mental Health Journal, 26, 177-190.

Rogoff, B. (1991). Apprenticeship in thinking: Cognitive development in social context. New York: Oxford University Press.

Rutter, M. (1990). Commentary: Some focus and process considerations regarding effects of parental depression on children. Developmental Psychology, 26, 60-67.

Sameroff, A. J., \& Fiese, B. (2000). Transactional regulation: The developmental ecology of early intervention. In J. P. Shonkoff, \& S. J. Meisels (Eds.), Handbook of early childhood intervention (2nd ed., pp. 135-159). New York: Cambridge University Press.

Secco, M. L., Ateah, C., Woodgate, R., \& Moffatt, M. E. (2002). Perceived and performed infant care competence of younger and older adolescent mothers. Issues in Comprehensive Pediatric Nursing, 25, 97-112.

Sheridan, S., \& Edwards, C. P. (2006). Parent Engagement and Child Learning, Birth to Five: The Getting Ready Project. Unpublished raw data.

Singh, S., \& Darroch, J. E. (2000). Adolescent pregnancy and childbearing: Levels and trends in developed countries. Family Planning Perspectives, 32, 14-23.

Smith, J. R., Brooks-Gunn, J., \& Klebanov, P. K. (1997). Consequences of living in poverty for young children's cognitive and verbal ability and early school achievement. In G. Duncan \& J. Brooks-Gunn (Eds.), Consequences of growing up poor (pp. 132-189). NY: Russell Sage Foundation.

Stanton-Chapman, T. L., Chapman, D. A., Kaiser, A. P., \& Hancock, T. B. (2004). Cumulative risk and low-income children's language development. Topics in Early Childhood Special Education, 24, 227-237.

Teti, D. M., \& Gelfand, D. M. (1991). Behavioral competence among mothers of infants in the first year: The mediational role of maternal self-efficacy. Child Development, 62, 918-929. 